\title{
Reform of the system of social insurance indispensable for Albania
}

The Confederation of Independent Trade Unions of Albania (BSPSH) sets down in its statute and programme the protection of the economic and social interests of the working class. For this reason, BSPSH has, since its foundation, paid particular attention to the protection of pensioners, as the incomes of this group have been, and still remain, low and insufficient. Or, expressed in other terms, society is not reimbursing to pensioners the contribution of their many working years.

Some changes concerning the reform of the system of social insurance are yet to be implemented.

It should be acknowledged that, during the period of the former regime, the system of social insurance was at its most accommodating, for the following three reasons:

1. a low number of pensioners (compared to the population of the country)

2. a simple calculation formula: the pension was $70 \%$ of the average wage of three working years in the last ten (at the age of retirement and when the worker has performed the required number of working years)

3. the high rate of employment assured a fair amount of rapport between employees paying contributions and pensioners. According to data for 2005 for both the public and the private sectors (excluding agriculture), however, there were 369000 pensioners while the number of contributing workers was 362000 . This is not a normal ratio. What has led to such an inopportune situation?

The main reason remains the implementation of 'shock therapy' which has destroyed industrial and agricultural enterprises with the result that $60 \%$ of workers remain jobless. In reality, what has been implemented is just 'shock' and now, despite sixteen years of transition, the much-requested 'therapy' has yet been little realised. It is a fact that, at present, there are 390000 working people in both the public and the private sector (excluding agriculture), while the public sector once contained 908000 working people.

What has happened to the population of the unemployed? Most have emigrated; some are still unemployed; while a small part has obtained early pensions.

The decrease in employed people and the artificial increase in pensioners has created a critical situation between contributors and beneficiaries. This, in turn, has brought about the low pensions, as illustrated in the table below:

Table 1 - Average wages and average pensions in the public sector

\begin{tabular}{|l|c|c|}
\hline Nominal indicator & $\mathbf{1 9 9 0}$ & $\mathbf{2 0 0 5}$ \\
\hline Nominal average pension & 401 & 9261 \\
\hline Average nominal salary & 570 & 26808 \\
\hline Index of prices & 100 & 24.6 \\
\hline
\end{tabular}




\begin{tabular}{|l|c|c|}
\hline Nominal indicator & $\mathbf{1 9 9 0}$ & $\mathbf{2 0 0 5}$ \\
\hline Real average pension & 401 & 376 \\
\hline Real average salary & 570 & 1090 \\
\hline Average pension as a percentage of average salary & 70.4 & 34.5 \\
\hline
\end{tabular}

The data in Table 1 reveals that average salary has increased more than the inflation index; at the same time, the nominal pension for industrial workers has increased more or less in line with the inflation index. Existing pensioners (after sixteen years of transition) benefit from a lower pension than before 1990 .

Pensions in the agricultural sector still remain symbolic.

Figure 1 - Average real monthly pension and average real monthly salary, 19902005

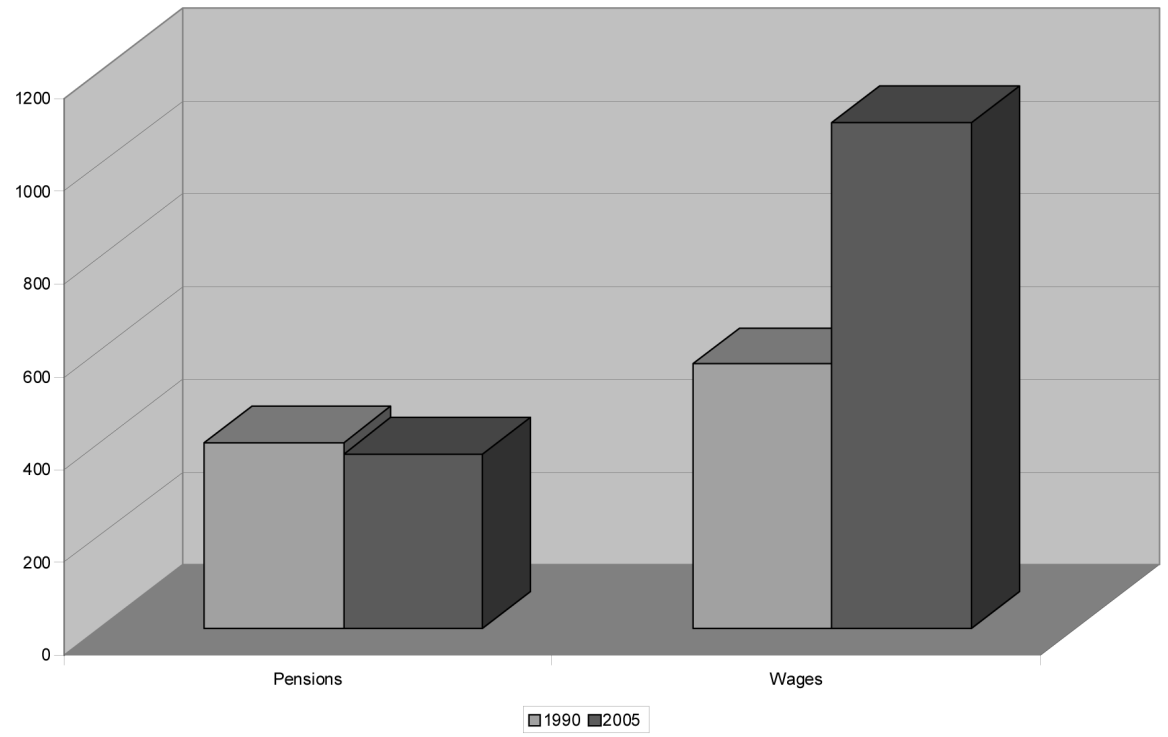

Figure 1 clearly indicates that, even though the average real salary has increased, the average real pension continues to be lower than in 1990.

To describe just how low are pensions, it is sufficient to mention that the indicator of the existence minimum (according to the calculations of the Institute of Labour, attached to the BSPSH) is $\$ 100$. This indicator is related to the UN recommendation that, for developing countries, the daily existence minimum is $\$ 2$.

The other negative occurrence in the pensions arena is that the major part of retired people are obtaining minimal pensions, regardless of their years of work or their contributions. Table 2 and Figure 2 demonstrate figures on pensions benefits for the first half-year of 2006. 
Table 2 - The distribution of urban pensioners according to the size of monthly pension

\begin{tabular}{|l|c|c|}
\hline Pensioner group & Number & $\%$ \\
\hline Up to 7850 lekë & 165160 & 57.8 \\
\hline $7851-10300$ lekë & 66767 & 23.4 \\
\hline $10301-13000$ lekë & 34150 & 11.9 \\
\hline $13001-15700$ lekë & 13962 & 4.9 \\
\hline 15701 lekë and more & 5748 & 2.0 \\
\hline Total & 285787 & 100.0 \\
\hline
\end{tabular}

Figure 2 - The distribution of monthly pensions for urban pensioners

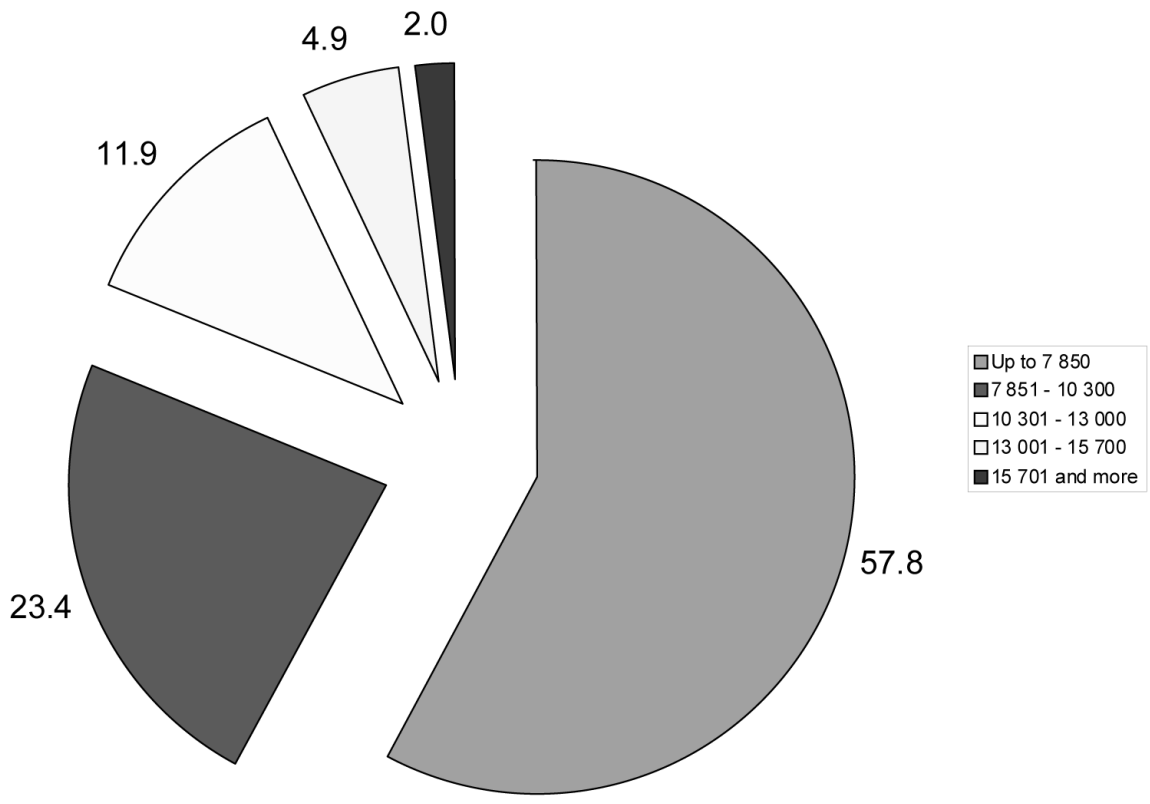

These figures clearly indicate that industrial workers are obtaining a minimal pension, even though only a small part of them have paid minimal contributions, in consequence of the high percentage of workers in the private sector who are paying minimal contributions, while many are not paying anything at all.

To tackle this situation, the Confederation of Independent Trade Unions of Albania is seeking the implementation of the Conventions of the International Labour Organisation and of the European Social Charter that have been ratified by our government. 
Article 12 of the Constitution of the Republic of Albania states:

Any worker has the right to social insurance on the age of retirement or when he is declared incapable of work according to the system settled by Albanian law.

The unsatisfactory nature of the system of social insurance is a result of the structure of the legislation and the non-implementation of the law.

Some of the drawbacks in the law are mentioned below:

1. Unfair treatment of pensioners who have retired before the approval of the most recent Social Insurance Law. Article 88 of this Law underlines:

Pensions determined by Law 4171 dated 13 April 1966 'Social Insurance in the Republic of Albania' will be accepted as they are and will not be the subject of any change, excluding indexation.

According to the operation of the law, pensioners are thus actually treated by two different laws: those who retired before the endorsement of the new law are subject to the previous one and the remainder to the most recent one. Pensioners subject to the previous law obtain, for the same contributions, lower pensions compared to the group subject to the most recent law.

BSPSH has presented its observations on this discrimination and the government has made some amendments to the pensions of those retiring before 1993 . To balance pensions, we have recommended two different methods of calculation:

a. method of the indexation of wages and pensions by the rate of inflation

b. method of coefficients. For example, if a group of pensioners previously obtained the maximum pension, they should still obtain the maximum pension.

2. Subsequent to the most recent law on pensions, many Albanian workers have lost their jobs as result of the economic reforms and many of them have retired early. This category of workers, for whom their years of work or contributions are not taken into account, obtains only a minimum pension.

3. The most recent law increased the age of retirement to 65 for men and to 60 for women.

BSPSH has requested that, for occupations facing difficult conditions, the age of retirement should be lower compared to other occupations. These suggestions have been presented to the National Labour Council and even though it has been promised, there has been, up to now, no change to the appropriate law.

4. Trade unions are opposed to increases in the age of retirement, on the grounds that the third age in Albania amounts to approximately $10 \%$ of the population, compared to the $15-25 \%$ in other European countries, while, at the same time, there is the high level of unemployment.

This increase in the age of retirement is not fair especially on men, who now face the situation of a total pension income, in the average ten years of retirement, which is only one-third of the contributions they have made over a working life of 35 years. 
5. There is a special social insurance fund for some people in particular professions: military personnel also obtain special pensions. This is discrimination against workers that have the same credits history (such as, for example, a scientist).

6. Another issue to be discussed is the ratio between contributors and pensioners (or the ratio between the minimum and the maximum pension).

In line with the legislation of Albania, we share the opinion that there is a contradiction within the law. On the one hand, it is accepted that the ratio between the maximum and the minimum contribution should be 5:1 while, on the other, that the ratio between the minimum and maximum pension should be 1:1. Consequently, employees paying higher contributions will not obtain bigger pensions.

The Law on Social Insurance is implemented strictly neither by the government, the Institution of Social Insurance or by employers. Below we present some of the areas of violation.

a. Firstly, Article 2 of the Law on Social Insurance states:

Contributions will guarantee the payment to many to recompense the drop in income to a certain amount that will at least cover a minimum standard of living as defined by the Council of Ministers.

In spite of the frequent requests from trade union organisations and despite the recommendation of the ILO, the government has not yet declared a minimum standard of living.

In 1998, BSPSH, with the financial and methodical support of the European Trade Union Institute (in strict collaboration with its Institute of Labour), published a monograph Welfare and the Minimum Standard of Living. The document has been translated into English and printed in that language. At the heart of the indicators of the survey, the existence minimum in Albania was calculated at $\$ 100$ and, for an employed person, $\$ 200$. These calculations are according to the recommendations of the UN.

It is a paradox that the Institute of Statistics declares $\$ 50$ (per month) as the minimum standard while for food items alone, the minimum required is $\$ 70$.

b. Secondly, the requirements of the law as regards the indexation of pensions have not been implemented.

c. Thirdly, the law on the collection of contributions has been violated.

Surveys by our Institute of Labour indicate that the level of informality in the private sector (outside of the agricultural sector) is approximately $40 \%$, while another negative phenomenon is the making of minimum contributions (i.e. contributions not being paid according to the real salary). These phenomena carry two negative consequences for employees:

1. the budgeted incomes of the Institute of Social Insurance will be reduced and, for the time being, this in turn means a lesser possibility to increase pensions in payment

2. employees who have been working without paying contributions will not benefit from pensions during retirement. At that point, society will need to find other ways to fulfil the living standards of this group. 
The frontlines in the war against informality and corruption in the field of social insurance need to be occupied by the structures of the state and by the social partners.

Recently, the government declared that the Institute of Social Insurance should pass from being within the direction of the Ministry of Labour to being within that of the Ministry of Finance. We do not think that this is an appropriate move since social insurance is a social issue and should, of necessity, be directed from within the Ministry of Labour.

Pensioners are interested in real pensions since, in a market economy, pensions are depreciated by prices. The level of increases applied to pensions has been low and lower than the guarantee to double pensions by the end of the period of the legislature (as was promised in the election campaign). Another issue here is that it was not specified in the programme as to which pension would be doubled: the minimum pension or the one actually being paid.

We share the opinion that all the possibilities for pensioners to obtain decent pensions should be exhausted.

With this purpose in mind, we suggest as below:

a. firstly, it is indispensable that we map long-term, medium-term and short-term strategies for the socio-economic development of our country. This will require political stability and the increase in sources of eastern capital

b. secondly, the gradual decrease in the informal sector and in corruption will create the conditions for a fair distribution of incomes. With the existing level of development in the country, as long as the informal sector and corruption are fought, this will automatically increase pensions in payment

c. thirdly, we need to increase voluntary insurance contributions, especially for emigrants, as the statistics indicate that one million people have left our country, most of them of working age. This will not only create the conditions to increase pensions in payment but also provide the opportunity for this group to earn pensions in our country at the age of their retirement.

Another important task is to unify the contributions of emigrants in the country of origin with contributions in the host country.

d. Fourthly, analysis of all this material clearly shows the necessity of a wholesale reform of the system of social insurance in Albania.

In reviewing the system of social insurance, we are looking for the assistance of the ILO and the European Trade Union Institute of the European Trade Union Confederation, as well as other international structures.

This will need to be carried out in the view of social solidarity.

Nevertheless, our trade union organisation will be actively engaged in this purpose, aiming to map a contemporary law that will build a fair balance between contributions and pensions. 